Original Research Paper

\title{
A Multimodal Biometric System using Global Features for Identical Twins Identification
}

\author{
${ }^{1,2,3}$ Bayan Omar Mohammed and ${ }^{1,2}$ Siti Mariyam Shamsuddin \\ ${ }^{1}$ UTM Big Data Centre, IbnuSina Institute for Scientific and Industrial Research, \\ Universiti Teknologi Malaysia, Johor, Malaysia \\ ${ }^{2}$ Faculty of Computing, Universiti Teknologi Malaysia, Johor, Malaysia \\ ${ }^{3}$ College of Science and Technology, University of Human Development, Sulaimani, KRG, Iraq
}

Article history

Received: 26-06-2017

Revised: 29-12-2017

Accepted: 18-01-2018

Corresponding Author: Bayan Omar Mohammed UTM Big Data Centre,

IbnuSina Institute for Scientific and Industrial Research, Universiti Teknologi Malaysia, Johor, Malaysia

Email: bayan.omar@uhd.edu.iq

\begin{abstract}
Pattern recognition studies are currently focusing on twin's biometric identification. The system of twins' biometric Identification can potentially differentiate the individual's biometric pattern. With the new Unimodal biometric identification, identical twins are precisely and reliably identified, with well exposure of certain traits. However, it is much more challenging to identify identical twins as they share so many similarities between them, as opposed to identifying the non-twins. Therefore, this study proposes the use of more than one biometric trait with global features. Pattern recognition application includes extracting and selecting meaningful features and this has brought to the key question in twin handwriting-fingerprint identification: How to obtain features from many writing styles and shapes of twin handwritingfingerprint in order that the reflection of the right person between twins can be obtained. Global with Aspect United Moment Invariant for the extractions of global feature using the identical twin multi-biometric identification is thus proposed by this study.
\end{abstract}

Keywords: Identical Twin, Global Features, Multimodal Biometric, Identification, AUMI, Similarity Measurement

\section{Introduction}

Biometric-based identification and verification systems will soon be leaders in the technology of human identification (Koda et al., 2016; Karahan et al., 2016). These systems are equipped with applications that control access to premises as well as computers and the ability to decrease fraudulent transaction incidences in electronic commerce and dampen unauthorized immigration (Hamid and Faez, 2013). Somehow, in the case of twins, identifying their biometric is difficult unlike identifying non-twins. As Eliabeth et al. (2015) had stated: The amount of similarities shared by identical twins is astonishing. Thus, in the arena of pattern recognition and computer vision, twins' biometric identification has been the researched subject among many. In certain situations in fact, it is the only method that could identify an actual person's biometric pattern from a group of individuals (Muhammed and Shamsuddin, 2017; Hamid and Faez, 2013; Narayanan and Shmatikov, 2005; Umair et al., 2009; Neves and Proenc, 2016).
The unimodal biometric identification for identical twins is now considerably more accurate and reliable (Eliabeth et al., 2015; Leng and Shamsuddin, 2012; Muhammed and Shamsuddin, 2012) and certain traits exhibit sound performance. Still, there are issues with respect to the technology itself. Further, among the past works on identical twins' identification or verification with the application of the Unimodal biometric system include: Wonder Ears, which employs images of ears to identify identical twins (Nejati et al., 2012), new multimodal database from the biometric traits of twins (Hamid and Faez, 2013). Discriminability between the fingerprints of twins (Jain et al., 2001), DNA analysis (Jain et al., 2002), computational discriminability analysis on the fingerprints of twins (Liu and Srihari, 2009), '3D Face Recognition' method to recognize the face of identical twins (Vipin et al., 2011), facial marks analysis to differentiate identical twins (Srinivas et al., 2012), 'Double Trouble' method for recognising identical twins' by face (Paone et al., 2014). However, Muhammed and Shamsuddin (2012) opined that all these 
studies were physiological in nature which means that changes are not likely to happen to them.

For sharing one zygote, identical twins have identical genetic makeup. Thus, it is difficult to identify them (Fig. 1). The application of more than one biometric trait with Global features is thus recommended as a solution to this problem, hence, the introduction of the multimodal biometric system employing both the physical and behaviour trait. A combination of countless sources obtained from countless biometric traits is employed in this system. Employing this system, without exact biometric identifier, user is still able to enrol as authentication can still be done using other traits. Thus, enrolment problem can be solved using this system, proving the universality of this system. Multimodal biometric is thus usable in the analysis of identical features to allow the extraction of features' unique characteristics, after which, further examination of the written texts and minutiae patterns versus the original ones, can performed. Additionally, in the past works for twins' biometric, the global (holistic) features of the cursive word or shape were not treated as one whole object.

\section{Individuality of Twins Multi-Biometric}

As theorized by some scholars (Kauba et al., 2016; Easwaramoorthy et al., 2016; Eliabeth et al., 2015), a person's handwriting-fingerprint can represent his/her nature. This shows that the permanency of writing and fingerprint style of a person, just like their personality. This study obtained the data in UHD for 20 twins. Here, 4 samples were produced by each twin for each biometric. Figure 2 presents the samples from the exact individual in pairs of twins as well as samples with differing pairs. As evidenced, both the writings and fingerprints demonstrate more similarity being generated by both individuals in a pair of twins. Nevertheless, there appears dissimilarity when the writings and fingerprints are generated by the different pair. A minor difference has also been discovered in the writings and fingerprints that the exact individual in a pair of twins produce.

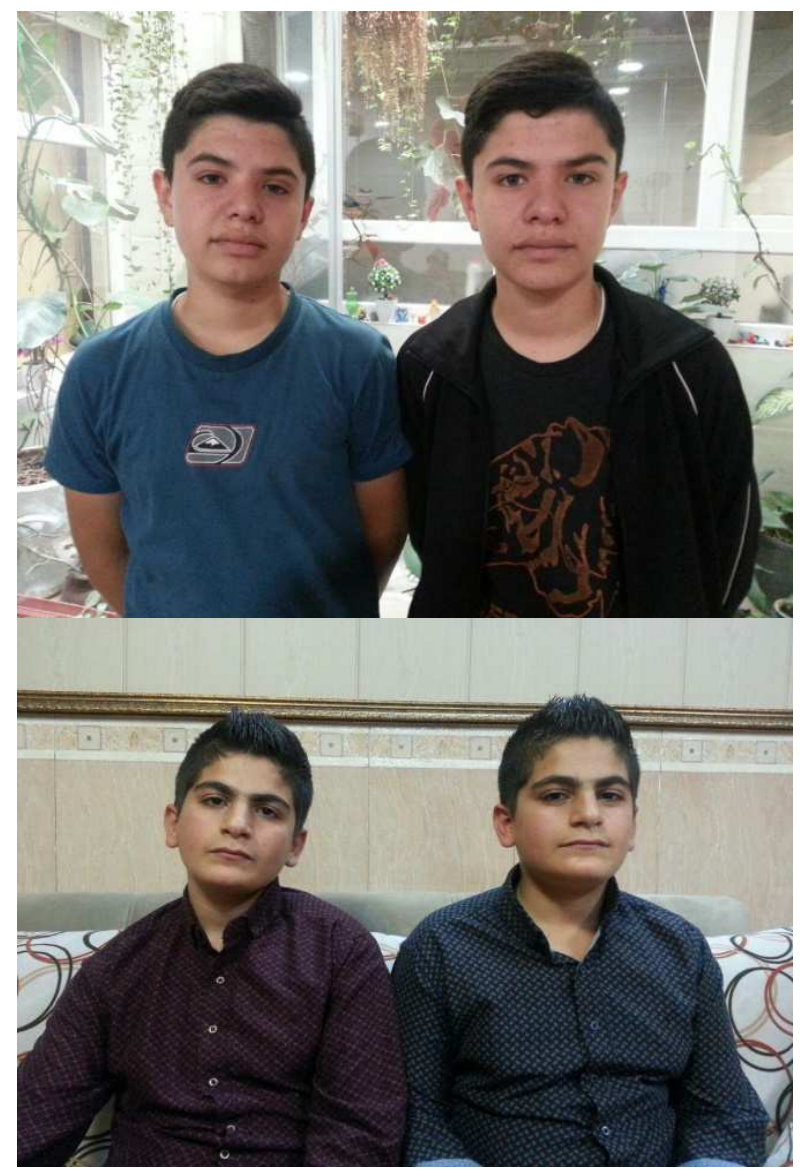

Fig. 1: A pair of identical twins from the identical twins dataset

\begin{tabular}{|c|c|c|c|c|c|c|c|}
\hline \multicolumn{2}{|c|}{ Twin number a7 } & \multicolumn{2}{|c|}{ Twin number b7 } & \multicolumn{2}{|c|}{ Twin number al4 } & \multicolumn{2}{|c|}{ Twin number b14 } \\
\hline Handwriting & Fingerprint & Handwriting & Fingerprint & Handwriting & Fingerprint & Handwriting & Fingerprint \\
\hline & & & & & & & \\
\hline & & & & & & & \\
\hline 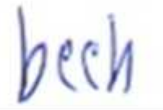 & & & 2 & & & & \\
\hline en & & & & 00010 & & & 추 \\
\hline
\end{tabular}

Fig. 2: Handwriting-fingerprint for both person in twins 
Defined difference appears to be present in writings and fingerprints that both individuals in a pair produce even though the height of shape seems similar in identical twins. Based on these findings, it can be said that even identical twins differ particularly in terms of handwriting and fingerprint, which has been termed 'Individuality of Handwriting-fingerprint' which is assessable using the variances. Here, as suggested by Easwaramoorthy et al. (2016), Patil et al. (2016) and Eliabeth et al. (2015), the value of the person's feature or the intra-class, should be lower than that of different persons or the inter-class. Additionally, features with the least similarity error for one person in a pair of twins (intra-class) and the most similarity error for both individuals in a pair of twins (inter-class) demonstrate the soundness as well as acceptableness of individual features (Patil and Wagh, 2016). This shows the need to obtain the individual features from the samples of handwritten-fingerprint to allow the identification of the individual in a pair of twins.

\section{Unique Representation with Global Features in Identical Twin}

The global features that could handle images of twin multi-biometric for identification purpose are proposed in this study. This method is employed to extract feature and it is an adaptive method. Using this method, the class is discretely improved since it relocates the feature points of individual twin's class to better places, which assures more efficient depiction of individual characteristics for each biometric modality prior to their usage in the matching process. Identification of twins with the shape of handwritten and fingerprint have been presented by many pattern recognition researchers (Patil et al., 2016; Muhammed and Shamsuddin, 2012; 2017). Meanwhile, the visual domain comprises the application of shape feature and according to Azah et al. (2010), shape is also a key feature in describing image content. It is however, not easy to extract features that accurately denote and exemplify the shape of a twin in identical pair. Thus, the proposal of a state-of-the-art system for identical twins becomes the first objective of this study. The proposed system comprises Multimodal biometric identification with the incorporation of countless modalities.

Further, the inclusion of algorithm of Aspect United Moment Invariant (AUMI) from Azah et al. (2010) is this study's second objective. The use of AUMI allows the extraction of a good set of global features which denote the twin handwriting-fingerprint from the region and the boundary representation of a fingerprint in terms of word and shape. In the process of identifying twin, the AUMI extracted features endure the test of individuality of handwriting and fingerprint.
Meanwhile, this study's next objective is to analyse the efficiency of global features. This is for minimising the variation for intra-class while maximising the variation for inter-class for twins' handwriting-fingerprint's individuality in the context of biometric Identification. A method comprising a procedure is used to achieve this purpose and this method is crucial since twin identification demands a technique that fulfils the 'individuality' of Multimodal biometric. Figure 3 illustrates the new proposed procedure for achieving better identification of handwriting-fingerprint of pair of twins.

\section{Multi-Biometric Shape Representations for Identical Twin}

The pattern recognition field has generated countless methods for shape representation and depiction of features extraction from an image. Using two different approaches, twin handwriting-fingerprint shape can be handled, generally. These approaches are: Analytic (local/structural) approach and holistic (global) approach. There are two methods to each approach which are: Region-based or whole region shape method and contour-based or contour only method. For the purpose of this study, the holistic approach has been chosen. This approach involves the depiction of the whole image shape, which is appropriate for this study because the twin handwriting-fingerprint shape has to be extracted as one single entity. In other words, it cannot be divided. Also, as assurance of the application of the most appropriate technique to preserve the individuality concept of twin handwriting-fingerprint in twin biometric identification, this study has selected the global method exploration. Meanwhile, as for the other approach, that is, the analytic approach, it involves image depiction in segments.

\section{AUMI with Twin Multi-Biometric}

The extraction of individual features from Twin Multi-biometric shape demands an effective technique. With respect to handwriting, Azah et al. (2010) and Zhang and $\mathrm{Lu}$ (2002) mentioned shape as opposed to character, to demonstrate greater individuality level. Thus, the United Moment Invariant (UMI) (Yinan et al., 2003) is useful for global features' extraction from the handwriting and shape of fingerprint produced by twins. UMI was formulated based on $\mathrm{Hu}$ (1962) Geometric Moment Invariant (GMI) and Chen (1993) Improve Moment Invariant (IMI). In this context, the feasibility of GMI for representation of region in subtle situation has been proven in the work of Chen (1993), but considering that boundary representation requires high computational times, IMI is proposed for boundary and quicker computation. 


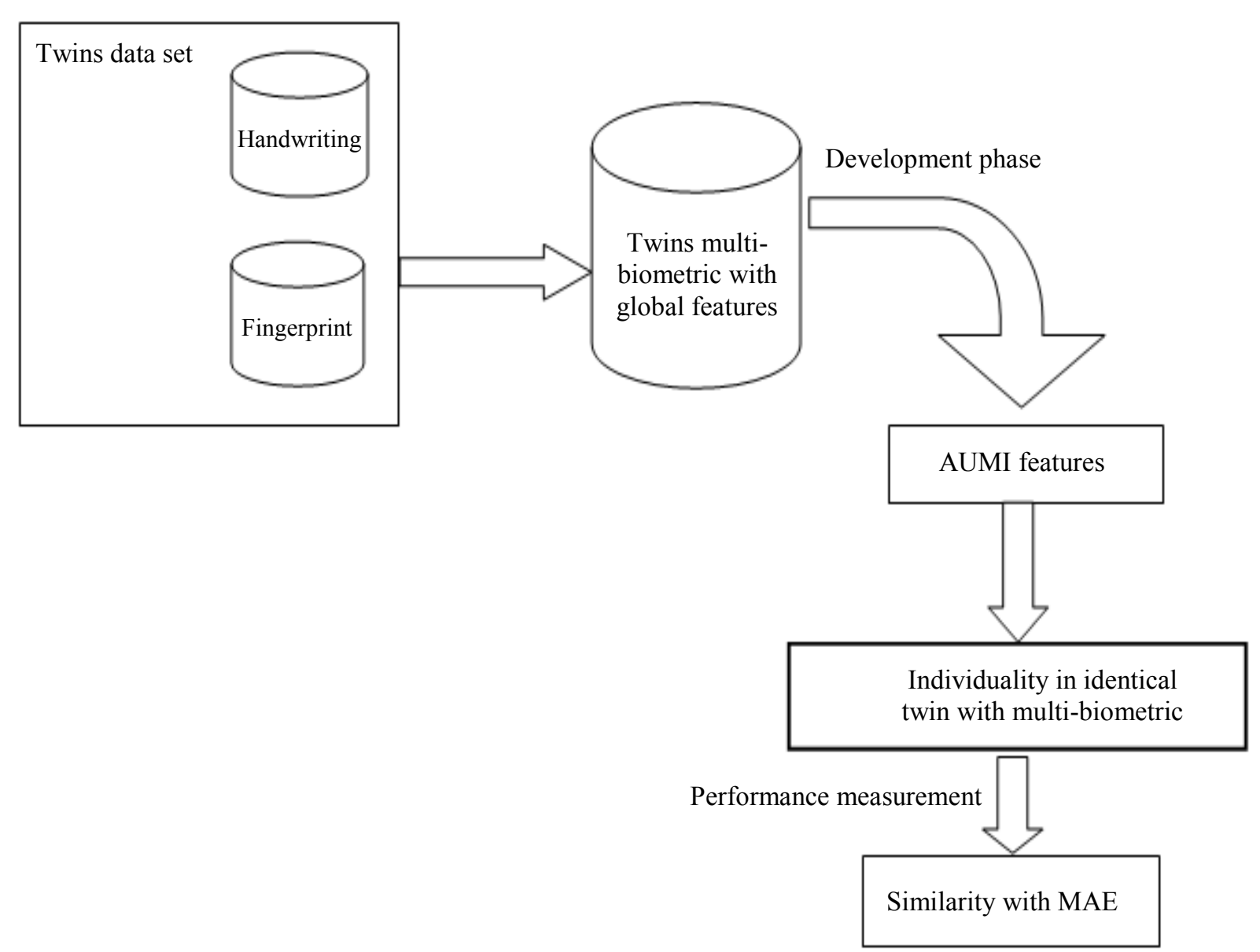

Fig. 3: New Framework for multi-biometric identification for a pair of twins

The image's region and boundary need to be constantly and independently extracted to assure quality feature in image representation (Yinan et al., 2003). Here, Yinan et al. (2003) proposed the use of UMI because of its capacity in effectively separating the shape of image consistently on region as well as on boundary. However, there are issues regarding the scaling factor utilised in UMI (Hu, 1962), which have led to the recommendation by Azah et al. (2010) of the use of the scaling factor of Aspect Invariant in Aspect United Moment formulated by Feng and Keane (1994). The application of this scaling factor enhances the invariant features without normalization of size. Therefore, the proposed AUMI algorithm also includes the aspect's scaling. With the use of this scaling, the invarianceness of handwriting-fingerprint for twin could be preserved in the direction of $\mathrm{X}$ and $\mathrm{Y}$, characterizing the human's handwriting-fingerprint of twin. Also, the scaling enables the consistent and subtle extraction of the global word and the fingerprint features shape from both region and boundary representation by way of invarianceness from twin's handwriting-fingerprint.

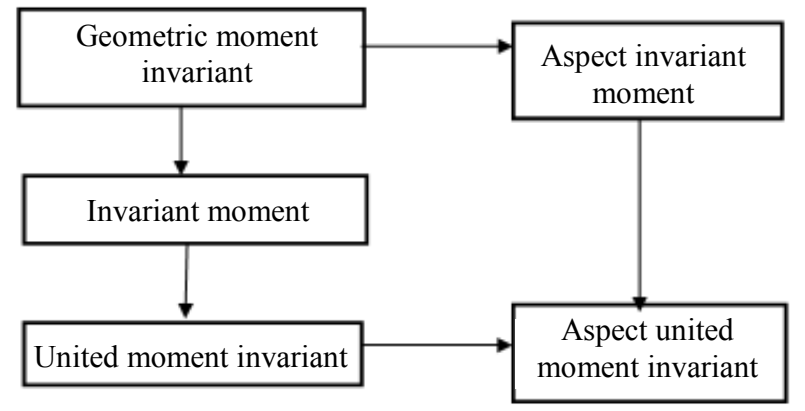

Fig. 4: Aspect United Moment Invariant

Azah et al.'s (2010) AUMI allows the global features' extraction from the region and boundary of (word or shape) in separate and continuous manner as representation of an individual in a twin. Here, the fusion embedded scaling factor of Aspect is created (Feng and Keane, 1994) into the UMI (Yinan et al., 2003), as can be referred in Fig. 4. This instantly assumes the capacity of these two functions of moment into the proposed Aspect United Moment Invariant. Yinan et al.'s (2003) UMI has association with geometrical representation that 
considers Normalized Central Moment equations of GMI (Hu, 1962) and Boundary Representation of IMI (Chen, 1993). Lastly, Azah et al.'s (2010) AUMI comprises 8 features with the construction of Yinan et al. (2003) UMI, as shown below:

$\theta_{1}=\frac{\sqrt{\varnothing_{2}}}{\varnothing_{1}}$

$\theta_{2}=\frac{\varnothing_{6}}{\varnothing_{1} \varnothing_{4}}$

$\theta_{3}=\frac{\sqrt{\varnothing_{5}}}{\varnothing_{4}}$

$\theta_{4}=\frac{\varnothing_{3}}{\varnothing_{2} \varnothing_{4}}$

$\theta_{5}=\frac{\varnothing_{1} \varnothing_{6}}{\varnothing_{1} \varnothing_{3}}$

$\theta_{6}=\frac{\left(\varnothing_{1}+\sqrt{\varnothing_{2}}\right) \varnothing_{2}}{\varnothing_{6}}$

$\theta_{7}=\frac{\varnothing_{1} \varnothing_{5}}{\varnothing_{3} \varnothing_{6}}$

$\theta_{8}=\frac{\varnothing_{3}+\varnothing_{4}}{\sqrt{\varnothing_{5}}}$
As $\varphi_{i}$ denotes large values, the natural logarithm is employed. As such, below is obtained:

$$
\text { for } i=1 \text { to } 7 ; \theta_{i} \leftarrow \log 10 \varphi_{i}
$$

\section{Twin Multi-Biometric with Global Extracted Feature (GEF)}

Table 1 shows the extracted word images sample of handwriting produced by twin. What can be seen in the table are the original extracted features after the global feature, which are the Aspect Invariant Moment (Aspect), United Moment Invariant (UMI), Aspect United Moment Invariant (AUMI) as well as macro feature extraction (MFE).

Table 2 illustrates the extracted the sample of twin's fingerprint images of shape. Both the original extracted features and the global feature are shown in the table and they include Geometrical minute feature extraction (GMFE), United Moment Invariant (UMI), Aspect Invariant Moment (Aspect), Geometric Moment Invariant (GMI), as well as Aspect United Moment Invariant (AUMI).

The system of identification employs a group of eatures that denotes the individuality and characteristics of an individual in a twin and only the vital features are extracted and selected. Somehow, in twin identification, extraction and selection are rather difficult to perform. This calls for the utilisation of the multi-biometric features from the data storage in identifying twin.

Table 1: Invariant features of twin number 7 by different algorithms

\begin{tabular}{llrrllllll}
\hline bceh & & F1 & F2 & F3 & F4 & F5 & F6 & F7 & F8 \\
\hline GMI & a & 19.5899 & 381.6335 & 2.6926 & 2.6496 & 7.0248 & 5.1721 & 6.4469 & -- \\
& b & 19.2375 & 361.0587 & 2.5265 & 2.4890 & 6.1995 & 4.7262 & 5.4285 & -- \\
Aspect & a & 18.8347 & 376.2823 & 7.0384 & 7.9596 & 1.8833 & 1.5714 & 4.9230 & -- \\
& $\mathrm{b}$ & 18.1444 & 344.3009 & 6.4421 & 7.2856 & 1.5778 & 1.2334 & 4.1239 & -- \\
UMI & $\mathrm{a}$ & 0.9933 & 0.9908 & 1.0003 & 0.9521 & 0.9555 & 1.0537 & 0.9610 & 2.0503 \\
& $\mathrm{~b}$ & 0.9844 & 0.9843 & 1.0004 & 0.9976 & 1.0125 & 1.0034 & 1.0135 & 2.0024 \\
AUMI & $\mathrm{a}$ & 1.0280 & 0.0900 & 1.7240 & 0.3362 & 0.0096 & 100.9817 & 3.7346 & 5.7076 \\
& $\mathrm{~b}$ & 1.0336 & 0.0946 & 1.7239 & 0.3363 & 0.0100 & 96.5498 & 3.5544 & 5.7088 \\
Macro & $\mathrm{a}$ & 7.3061 & 3.1300 & 2.1606 & 0.7039 & 9.3260 & 9.3260 & 0.2293 & 8.6080 \\
& $\mathrm{~b}$ & 7.6824 & 2.3400 & 1.8381 & 0.7216 & 5.8710 & 1.5393 & 0.1691 & 6.2170 \\
\hline
\end{tabular}

Table 2: Invariant features of twin number 7 by different algorithms

\begin{tabular}{|c|c|c|c|c|c|c|c|c|c|}
\hline & & F1 & $\mathrm{F} 2$ & F3 & F4 & F5 & F6 & F7 & F8 \\
\hline \multirow[t]{2}{*}{ GMI } & $\mathrm{a}$ & 20.0601 & 363.5930 & 2.5939 & 2.5712 & 6.6206 & 5.8891 & 3.8856 & -- \\
\hline & $\mathrm{b}$ & 20.2399 & 37.8910 & 2.6470 & 2.6291 & 6.9262 & 2.3313 & 2.8285 & -- \\
\hline \multirow[t]{2}{*}{ Aspect } & $\mathrm{a}$ & 8.4807 & 70.6361 & 1.6392 & 1.8510 & 1.0192 & 2.6367 & 2.6340 & -- \\
\hline & $\mathrm{b}$ & 7.3566 & 58.9641 & 9.0411 & 1.0253 & 3.1206 & 3.1206 & 8.2568 & -- \\
\hline \multirow[t]{2}{*}{ UMI } & $\mathrm{a}$ & 0.9505 & 1.1418 & 1.0007 & 0.9927 & 1.2526 & 8.3991 & 8.6942 & 2.0074 \\
\hline & $\mathrm{b}$ & 1.0379 & 1.0189 & 1.0003 & 0.2933 & 2.7728 & 3.4749 & 2.8784 & 4.4102 \\
\hline \multirow[t]{2}{*}{ AUMI } & $\mathrm{a}$ & 1.0107 & 0.1690 & 1.7250 & 0.3358 & 0.0187 & 53.0042 & 1.9872 & 5.7168 \\
\hline & $\mathrm{b}$ & 1.0109 & 0.0881 & 1.7217 & 0.3369 & 0.0098 & 100.9343 & 3.8238 & 5.6906 \\
\hline \multirow{2}{*}{$\begin{array}{l}\text { Geometrical } \\
\text { minute }\end{array}$} & $\mathrm{a}$ & 178.0000 & 162.0000 & 184.0000 & 190.0000 & 183.0000 & 168.0000 & 167.0000 & 159 \\
\hline & $\mathrm{b}$ & 199.0000 & 166.0000 & 212.0000 & 209.0000 & 198.0000 & 200.0000 & 167.0000 & 182 \\
\hline
\end{tabular}




\section{Similarity Measurement with MAE}

Mean Absolute Error (MAE) measures uniqueness and the example of MAE calculation can be referred in Tables 3 to 5 . As can be seen from the tables, there are 4 images employed for the representation of each individual. The value of MAE denotes the invarianceness of twin handwriting-fingerprint and it also offers the first image or reference image (Muhammed and Shamsuddin, 2017). The occurrence of small errors means that the image is almost identical to the reference image. The value of the overall results is used to compute MAE's average. MAE computation is as expressed below:

$$
M A E=\frac{1}{n} \sum_{i=1}^{f}\left|\left(x_{i}-r_{i}\right)\right|
$$

Where:

$n=$ Denotes the number of images

$x_{i}=$ Represents the current image

$r_{i}=$ Denotes the image of reference or location measure

$f=$ Represents the number of features

$i=$ Denotes the feature column of image

MAE matches with the individuality measurement of the individual twin handwriting-fingerprint in twin multi-biometric identification. Thus, this study has chosen the use of MAE function. Each twin of a pair has distinct features or characteristic with respect to their handwriting-fingerprint. The MAE function is used to measure the variance between twins' handwriting-fingerprint. Here, two handwritingfingerprints' similarity error obtained from detailed characteristics in the column which denote feature, is used. Thus, the variance between two handwritingfingerprint images for the features obtained from each column from the image's extracted invariant feature vector can be calculated. If low mean and standard division MAE value is attained, then, there is high similarity between the image and the reference or first image. On the other hand, if mean and standard division MAE value is high, then, there is low similarity between the image and the reference or first image. Simply stated, lowest value signifies highest similarity and vice versa. The classification of MAE function under robustness theory of statistical procedure has also been mentioned by other studies (e.g., Muhammed and Shamsuddin, 2012; 2017) and MAE function is also regarded as the most practicable and simplest solution. The pseudo code for this process is exhibited in Fig. 5.

Table 3: Intra-class MAE from AUMI features for twin multi-biometric for a10

\begin{tabular}{llllllllll}
\hline Image & F1 & F2 & F3 & F4 & F5 & F6 & F7 & F8 & MAE \\
\hline Handwriting & & & & & & & & \\
1a10 & 1.0323 & 0.1000 & 1.7242 & 0.3363 & 0.0126 & 76.9720 & 2.8343 & 5.7091 & -- \\
2a10 & 1.0209 & 0.1055 & 1.7242 & 0.3363 & 0.0115 & 85.5333 & 3.1863 & 5.7079 & 2.2331 \\
3a10 & 1.0230 & 0.1065 & 1.7242 & 0.3363 & 0.0115 & 84.9152 & 3.1569 & 5.7078 & 2.0710 \\
4a10 & 1.0272 & 0.1184 & 1.7242 & 0.3363 & 0.0127 & 76.7366 & 2.8398 & 5.7089 & 0.0662 \\
Mean Absolute Error for handwriting a10 & & & & & & & 1.0926 \\
Fingerprint & & & & & & & & \\
1a10 & 1.0119 & 0.1485 & 1.7240 & 0.3362 & 0.0164 & 60.2519 & 2.2644 & 5.7077 & -- \\
2a10 & 1.0402 & 0.1253 & 1.7240 & 0.3362 & 0.0131 & 73.3963 & 2.6833 & 5.7079 & 3.4046 \\
3a10 & 1.0628 & 0.1288 & 1.7240 & 0.3362 & 0.0129 & 72.9727 & 2.6111 & 5.7079 & 3.2855 \\
4a10 & 1.0516 & 0.1496 & 1.7244 & 0.3361 & 0.0153 & 60.2519 & 2.2462 & 5.7112 & 0.0160 \\
Mean Absolute Error for fingerprint a10 & & & & & & & \\
\hline
\end{tabular}

Table 4: Intra-class MAE from AUMI features for twin multi-biometric for b10

\begin{tabular}{|c|c|c|c|c|c|c|c|c|c|}
\hline Image & $\mathrm{F} 1$ & $\mathrm{~F} 2$ & F3 & $\mathrm{F} 4$ & F5 & F6 & F7 & F8 & MAE \\
\hline \multicolumn{10}{|c|}{ Handwriting } \\
\hline $1 b 10$ & 1.0260 & 0.1186 & 1.7240 & 0.3362 & 0.0127 & 76.4993 & 2.8347 & 5.7085 & -- \\
\hline $2 \mathrm{~b} 10$ & 1.0274 & 0.1164 & 1.7240 & 0.3362 & 0.0125 & 78.0525 & 2.8889 & 5.7080 & 0.4029 \\
\hline $3 \mathrm{~b} 10$ & 1.0230 & 0.1187 & 1.7240 & 0.3362 & 0.0128 & 76.1647 & 2.8316 & 5.7076 & 0.0855 \\
\hline $4 \mathrm{~b} 10$ & 1.0206 & 0.1105 & 1.7240 & 0.3362 & 0.0120 & 81.6596 & 3.0431 & 5.7078 & 1.3459 \\
\hline \multicolumn{9}{|c|}{ Mean Absolute Error for handwriting b10 } & 0.4586 \\
\hline \multicolumn{10}{|c|}{ Fingerprint } \\
\hline $1 \mathrm{~b} 10$ & 0.9765 & 0.1882 & 1.7252 & 0.3358 & 0.0223 & 46.0062 & 1.7844 & 5.7178 & -- \\
\hline $2 b 10$ & 0.9442 & 0.2601 & 1.7253 & 0.3356 & 0.0329 & 32.2016 & 1.2905 & 5.7202 & 3.6040 \\
\hline $3 \mathrm{~b} 10$ & 1.0040 & 0.1724 & 1.7247 & 0.3359 & 0.0193 & 51.5573 & 1.9481 & 5.7139 & 1.4414 \\
\hline $4 \mathrm{~b} 10$ & 1.0233 & 0.1531 & 1.7251 & 0.3358 & 0.0165 & 59.2351 & 2.1937 & 5.7166 & 3.4318 \\
\hline \multicolumn{9}{|c|}{ Mean Absolute Error for fingerprint b10 } & 2.1193 \\
\hline
\end{tabular}


Table 5: Inter-class MAE from AUMI features for multi-biometric for twin number 10

\begin{tabular}{|c|c|c|c|c|c|c|c|c|c|}
\hline Image & F1 & $\mathrm{F} 2$ & F3 & F4 & F5 & F6 & F7 & F8 & MAE \\
\hline \multicolumn{10}{|c|}{ Handwriting } \\
\hline $1 \mathrm{a} 10$ & 1.0209 & 0.1055 & 1.7242 & 0.3363 & 0.0115 & 89.5333 & 3.1863 & 5.7079 & -- \\
\hline $2 \mathrm{a} 10$ & 1.0323 & 0.1000 & 1.7242 & 0.3363 & 0.0126 & 76.9720 & 2.8343 & 5.7091 & 1.6175 \\
\hline $3 \mathrm{a} 10$ & 1.0230 & 0.1065 & 1.7242 & 0.3363 & 0.0115 & 84.9152 & 3.1569 & 5.7078 & 0.5813 \\
\hline $4 \mathrm{a} 10$ & 1.0272 & 0.1184 & 1.7242 & 0.3363 & 0.0127 & 76.7366 & 2.8398 & 5.7089 & 1.6456 \\
\hline $1 \mathrm{~b} 10$ & 1.0260 & 0.1186 & 1.7240 & 0.3362 & 0.0127 & 76.4993 & 2.8347 & 5.7085 & 1.6757 \\
\hline $2 \mathrm{~b} 10$ & 1.0274 & 0.1164 & 1.7240 & 0.3362 & 0.0125 & 78.0525 & 2.8889 & 5.7080 & 1.4746 \\
\hline $3 \mathrm{~b} 10$ & 1.0230 & 0.1187 & 1.7240 & 0.3362 & 0.0128 & 76.1647 & 2.8316 & 5.7076 & 1.7176 \\
\hline $4 b 10$ & 1.0206 & 0.1105 & 1.7240 & 0.3362 & 0.0120 & 81.6596 & 3.0431 & 5.7078 & 1.0029 \\
\hline \multicolumn{9}{|c|}{ Mean Absolute Error for handwriting a10, b10 } & 1.2144 \\
\hline \multicolumn{10}{|c|}{ Fingerprint } \\
\hline $1 \mathrm{a} 10$ & 1.0402 & 0.1253 & 1.7240 & 0.3362 & 0.0131 & 73.3963 & 2.6833 & 5.7079 & -- \\
\hline $2 \mathrm{a} 10$ & 1.0628 & 0.1288 & 1.7240 & 0.3362 & 0.0129 & 72.9727 & 2.6111 & 5.7079 & 0.0653 \\
\hline $3 \mathrm{a} 10$ & 1.0516 & 0.1496 & 1.7244 & 0.3361 & 0.0153 & 60.2519 & 2.2462 & 5.7112 & 1.7029 \\
\hline $4 \mathrm{a} 10$ & 0.9765 & 0.1882 & 1.7252 & 0.3358 & 0.0223 & 46.0062 & 1.7844 & 5.7178 & 1.8386 \\
\hline $1 \mathrm{~b} 10$ & 0.9442 & 0.2601 & 1.7253 & 0.3356 & 0.0329 & 32.2016 & 1.2905 & 5.7202 & 3.5545 \\
\hline $2 \mathrm{~b} 10$ & 1.0040 & 0.1724 & 1.7247 & 0.3359 & 0.0193 & 51.5573 & 1.9481 & 5.7139 & 5.3565 \\
\hline $3 \mathrm{~b} 10$ & 1.0233 & 0.1531 & 1.7251 & 0.3358 & 0.0165 & 59.2351 & 2.1937 & 5.7166 & 2.8338 \\
\hline $4 b 10$ & 1.0119 & 0.1485 & 1.7240 & 0.3362 & 0.0164 & 60.2519 & 2.2644 & 5.7077 & 1.7023 \\
\hline \multicolumn{9}{|c|}{ Mean Absolute Error for fingerprint a10, b10 } & 2.1317 \\
\hline
\end{tabular}

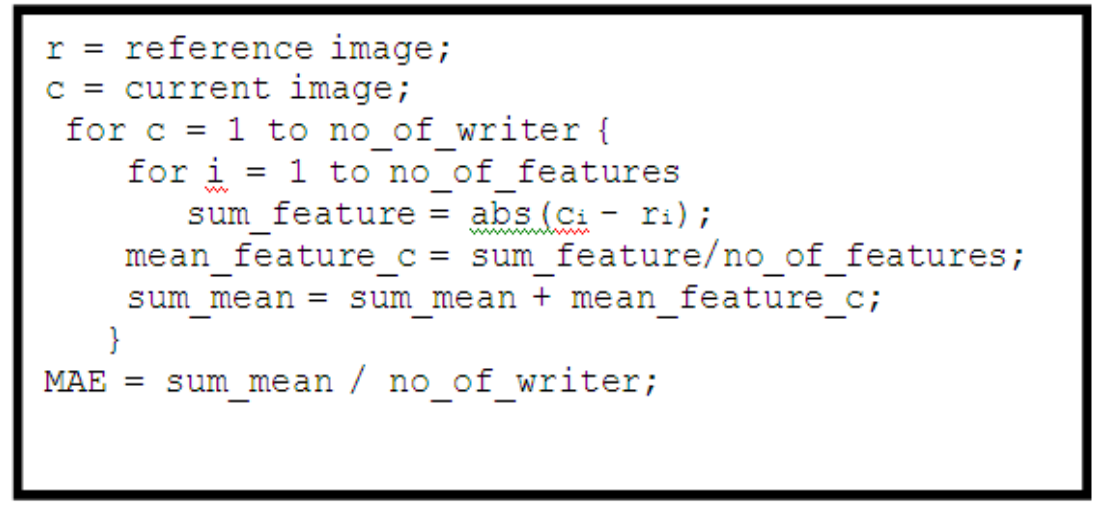

Fig. 5: Pseudo code of MAE analysis

\section{Similarity measurement with Intra-class and Inter- class with AUMI}

The analyses of intra-class and inter-class were performed on the obtained value of MAE. Intra-class contains features extracted from the exact twin or one twin. On the other hand, inter-class includes features extracted from both in a twin or different twin. Word of writing and fingerprint shape produced by twin for intraclass both necessitate smaller MAE value. Comparatively, the inter-class needs bigger MAE value. Thus, the individuality of twin handwriting-fingerprint would be observable.

Presented in Tables 3 through 9 are the intra-class measurement (measurement of one person in a twin or one twin) and the inter-class measurement (measurement of both persons in a twin or different twin) with respect to difference. Here, the MAE function is employed for shape and word. The intraclass can be referred in Tables 3, 4, 6 and 8. Here, the values of MAE are lower than those presented in Tables 5, 7 and 9; all tables employ the twin multi-biometric. In Tables 3 through 9, the analysability of MAE values is demonstrated in the twin handwriting-fingerprint verification with respect to individuality. As for Tables 3 and 4, lower MAE value can be seen which shows that as proven by Table 5, the feature between the handwriting and fingerprint from the same person in a twin demonstrates close feature value when it is contrasted with the handwriting and fingerprint produced by both twins. Lower MAE value can also be seen in Tables 6 and 8 which shows that as proven by Table 9, the feature between the handwriting and fingerprint produced by both persons in a twin evidences close feature value when it is contrasted with the handwriting and fingerprint produced by different twins. 
Table 6: Intra-class MAE from AUMI features for handwriting for twin number 1 and 2 (a, b)

\begin{tabular}{|c|c|c|c|c|c|c|c|c|}
\hline F1 & $\mathrm{F} 2$ & F3 & F4 & F5 & F6 & F7 & F8 & MAE \\
\hline \multicolumn{9}{|c|}{ Handwriting Twin $1(\mathrm{a}, \mathrm{b})$} \\
\hline 1.0354 & 0.1152 & 1.7242 & 0.3361 & 0.0122 & 79.4867 & 2.9178 & 5.7093 & -- \\
\hline 1.0326 & 0.1130 & 1.7242 & 0.3361 & 0.0120 & 80.8020 & 2.9741 & 5.7093 & 0.1721 \\
\hline 1.0330 & 0.1072 & 1.7242 & 0.3362 & 0.0114 & 85.2382 & 3.1368 & 5.7089 & 0.7478 \\
\hline 1.0339 & 0.1018 & 1.7239 & 0.3362 & 0.0110 & 89.7995 & 3.3039 & 5.7071 & 1.3397 \\
\hline 1.0358 & 0.1018 & 1.7240 & 0.3362 & 0.0110 & 87.6847 & 3.2193 & 5.7079 & 1.0645 \\
\hline 1.0336 & 0.1132 & 1.7241 & 0.3362 & 0.0110 & 80.7376 & 2.9702 & 5.7084 & 0.1637 \\
\hline 1.0346 & 0.1013 & 1.7239 & 0.3363 & 0.0107 & 90.2566 & 3.3188 & 5.7069 & 1.3988 \\
\hline 1.0332 & 0.1068 & 1.7242 & 0.3362 & 0.0113 & 85.5679 & 3.1482 & 5.7089 & 0.7904 \\
\hline \multicolumn{8}{|c|}{ Average MAE } & 0.7096 \\
\hline \multicolumn{9}{|c|}{ Handwriting Twin $2(a, b)$} \\
\hline 1.0318 & 0.1098 & 1.7241 & 0.3362 & 0.0117 & 83.1055 & 3.0619 & 5.7089 & -- \\
\hline 1.0347 & 0.0976 & 1.7239 & 0.3362 & 0.0103 & 93.6710 & 3.4440 & 5.7071 & 1.3708 \\
\hline 1.0299 & 0.1026 & 1.7241 & 0.3362 & 0.0109 & 88.7336 & 3.2760 & 5.7082 & 0.7316 \\
\hline 1.0300 & 0.1024 & 1.7241 & 0.3362 & 0.0109 & 88.9304 & 3.2831 & 5.7082 & 0.7571 \\
\hline 1.0311 & 0.1046 & 1.7241 & 0.3362 & 0.0111 & 87.1319 & 3.2127 & 5.7087 & 0.5230 \\
\hline 1.0322 & 0.1076 & 1.7242 & 0.3362 & 0.0114 & 84.8370 & 3.1241 & 5.7091 & 0.2246 \\
\hline 1.0315 & 0.1087 & 1.7242 & 0.3362 & 0.0116 & 83.9064 & 3.0919 & 5.7091 & 0.1041 \\
\hline \multicolumn{8}{|c|}{ Average MAE } & 0.0988 \\
\hline
\end{tabular}

Table 7: Inter-class MAE from AUMI features for handwriting for twin number 1 and 2 (a, b)

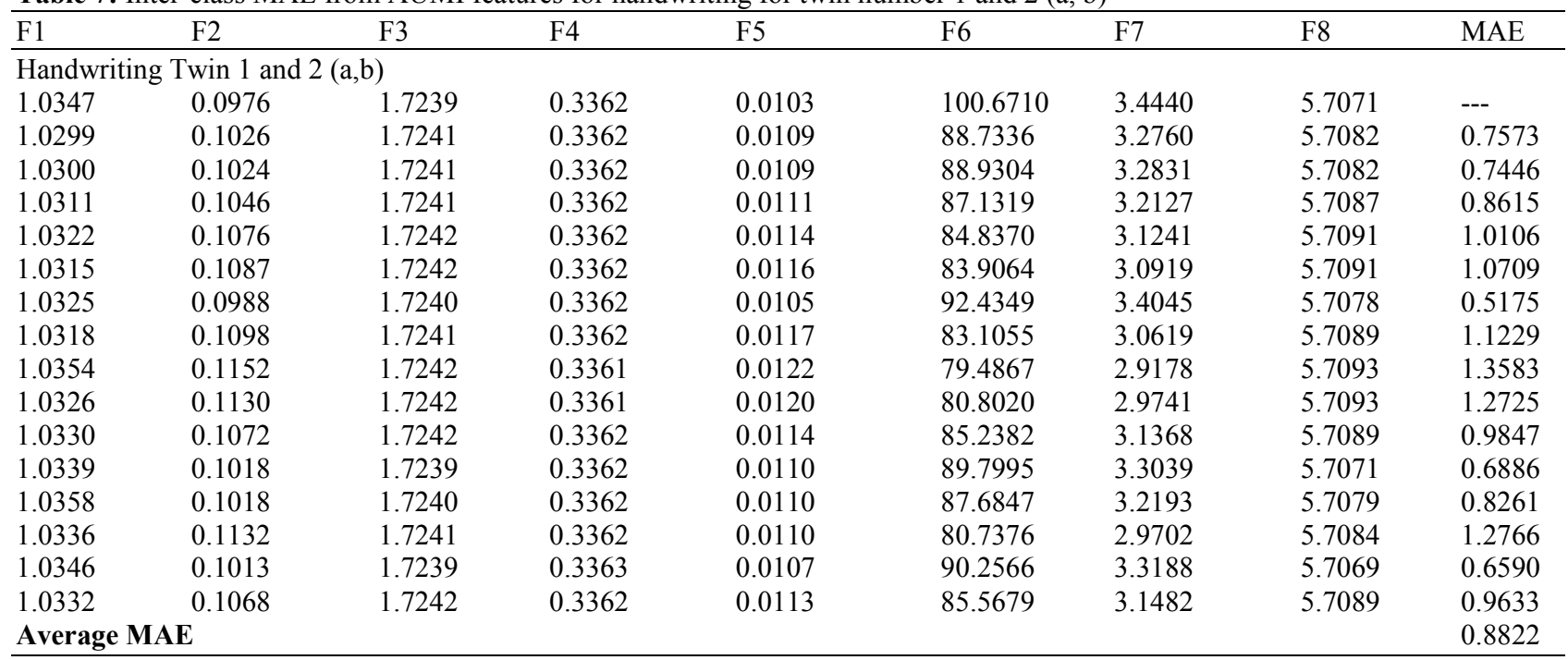

The similarity measurement process can apply any function that is in compliant with the similarity measurement rules between twin's features. This study has chosen MAE function because MAE function can be employed on limited data (as this study has). Also, MAE function demonstrates its appropriateness with the individuality of the analysis of twin handwritingfingerprint. With respect to the analysis of intra-class and inter-class, comparison between intra-class and inter-class, the process of similarity measurement run. For this matter, the value of variance for intra-class should be lower than that of inter-class. This will guarantee that the individuality requirement of the twin handwriting-fingerprint is satisfied in order that it becomes pertinent in $\mathrm{TI}$.

\section{Experiment Result}

The outcomes of AUMI are highlighted in this work. This will allow the determination of this method's applicability in Twin multi-biometric identification. Comparison and analysis are also made involving AUMI and other techniques, so that the hypothesis on AUMI's positive value in TI can be determined. Accordingly, Table 10 presents the MAE value outcomes and as can be construed, more exploration on AUMI algorithm should be carried out in the TI domain. Also, the outcome of similarity error demonstrates the presence of smaller Uniqueness of authorship for intra-class (same individual in twin or both individuals in a twin) when comparison is 
performed with that of inter-class (both individuals in twin or different twin). This finding satisfies the individuality notion of twin handwriting-fingerprint in identification arena. Here, in terms of handwriting and fingerprint, lower value of MAE for intra-class is obtained in comparison to the value of MAE obtained for inter-class. This is factored by the fact that moment function is a representation of image.

Table 8: Intra-class MAE from AUMI features for fingerprint for twin number 1 and $2(\mathrm{a}, \mathrm{b})$

\begin{tabular}{|c|c|c|c|c|c|c|c|c|}
\hline $\mathrm{F} 1$ & $\mathrm{~F} 2$ & F3 & F4 & F5 & F6 & F7 & F8 & MAE \\
\hline \multicolumn{9}{|c|}{ Fingerprint Twin $1(\mathrm{a}, \mathrm{b})$} \\
\hline 1.0481 & 0.1603 & 1.7238 & 0.3362 & 0.0165 & 57.7984 & 2.0979 & 5.7069 & 0 \\
\hline 1.0169 & 0.1505 & 1.7235 & 0.3364 & 0.0165 & 59.6604 & 2.2343 & 5.7044 & 0.2553 \\
\hline 1.0107 & 0.1611 & 1.7248 & 0.3359 & 0.0178 & 55.5587 & 2.0847 & 5.7148 & 0.2877 \\
\hline 1.0226 & 0.1603 & 1.7259 & 0.3354 & 0.0261 & 37.4212 & 1.3818 & 5.7253 & 2.6437 \\
\hline 0.9363 & 0.1749 & 1.7240 & 0.3361 & 0.0226 & 47.3295 & 1.9214 & 5.7090 & 1.3475 \\
\hline 0.9024 & 0.2053 & 1.7237 & 0.3361 & 0.0285 & 38.8720 & 1.6370 & 5.7095 & 2.4491 \\
\hline 0.9756 & 0.2902 & 1.7253 & 0.3355 & 0.0344 & 29.8335 & 1.1563 & 5.7221 & 3.6430 \\
\hline 0.8951 & 0.2053 & 1.7240 & 0.3356 & 0.0282 & 39.6290 & 1.6370 & 5.7090 & 2.3554 \\
\hline \multicolumn{8}{|c|}{ Average MAE } & 1.6227 \\
\hline \multicolumn{9}{|c|}{ Fingerprint Twin $2(a, b)$} \\
\hline 1.0564 & 0.0629 & 1.7239 & 0.3363 & 0.0064 & 148.4058 & 5.3458 & 5.7064 & 0 \\
\hline 1.0490 & 0.0616 & 1.7240 & 0.3363 & 0.0063 & 150.5808 & 5.4608 & 5.7070 & 0.2874 \\
\hline 1.0644 & 0.0611 & 1.7239 & 0.3362 & 0.0061 & 184.0403 & 5.5053 & 5.7070 & 4.4756 \\
\hline 1.0305 & 0.1353 & 1.7248 & 0.3359 & 0.0144 & 67.4441 & 2.4819 & 5.7149 & 10.4927 \\
\hline 1.0178 & 0.1602 & 1.7237 & 0.3363 & 0.0175 & 56.1404 & 2.0994 & 5.7059 & 11.9574 \\
\hline 1.0142 & 0.1418 & 1.7242 & 0.3361 & 0.0156 & 63.2681 & 2.3703 & 5.7100 & 11.0309 \\
\hline 1.0305 & 0.0901 & 1.7238 & 0.3363 & 0.0096 & 101.1057 & 3.7337 & 5.7062 & 6.1211 \\
\hline 1.0178 & 0.1021 & 1.7239 & 0.3362 & 0.0110 & 100.8608 & 3.2916 & 5.7073 & 6.2103 \\
\hline \multicolumn{8}{|c|}{ Average MAE } & 6.3219 \\
\hline
\end{tabular}

Table 9: Inter-class MAE from AUMI features for fingerprint for twin number 1 and 2 (a,b)

\begin{tabular}{|c|c|c|c|c|c|c|c|c|}
\hline F1 & $\mathrm{F} 2$ & F3 & F4 & F5 & F6 & F7 & F8 & MAE \\
\hline \multicolumn{9}{|c|}{ Fingerprint Twin 1 and $2(a, b)$} \\
\hline 1.0644 & 0.0611 & 1.7239 & 0.3362 & 0.0061 & 184.0403 & 5.5053 & 5.7070 & 0 \\
\hline 1.0481 & 0.1603 & 1.7238 & 0.3362 & 0.0165 & 57.7984 & 2.0979 & 5.7069 & 8.1110 \\
\hline 1.0169 & 0.1505 & 1.7235 & 0.3364 & 0.0165 & 59.6604 & 2.2343 & 5.7044 & 7.9876 \\
\hline 1.0107 & 0.1611 & 1.7248 & 0.3359 & 0.0178 & 55.5587 & 2.0847 & 5.7148 & 8.2548 \\
\hline 1.0226 & 0.1603 & 1.7259 & 0.3354 & 0.0261 & 37.4212 & 1.3818 & 5.7253 & 9.4328 \\
\hline 0.9363 & 0.1749 & 1.7240 & 0.3361 & 0.0226 & 47.3295 & 1.9214 & 5.7090 & 8.7847 \\
\hline 0.9024 & 0.2053 & 1.7237 & 0.3361 & 0.0285 & 38.8720 & 1.6370 & 5.7095 & 9.3355 \\
\hline 0.9756 & 0.2902 & 1.7253 & 0.3355 & 0.0344 & 29.8335 & 1.1563 & 5.7221 & 9.9324 \\
\hline 0.8951 & 0.2053 & 1.7240 & 0.3356 & 0.0282 & 39.6290 & 1.6370 & 5.7090 & 9.2886 \\
\hline 1.0178 & 0.1602 & 1.7237 & 0.3363 & 0.0175 & 56.1404 & 2.0994 & 5.7059 & 8.2165 \\
\hline 1.0142 & 0.1418 & 1.7242 & 0.3361 & 0.0156 & 63.2681 & 2.3703 & 5.7100 & 7.7532 \\
\hline 1.0305 & 0.0901 & 1.7238 & 0.3363 & 0.0096 & 101.1057 & 3.7337 & 5.7062 & 5.2984 \\
\hline 1.0178 & 0.1021 & 1.7239 & 0.3362 & 0.0110 & 88.8608 & 3.2916 & 5.7073 & 6.0929 \\
\hline 1.0564 & 0.0629 & 1.7239 & 0.3363 & 0.0064 & 148.4058 & 5.3458 & 5.7064 & 2.2378 \\
\hline 1.0490 & 0.0616 & 1.7240 & 0.3363 & 0.0063 & 150.5808 & 5.4608 & 5.7070 & 2.0950 \\
\hline 1.0305 & 0.1353 & 1.7248 & 0.3359 & 0.0144 & 67.4441 & 2.4819 & 5.7149 & 7.4841 \\
\hline \multicolumn{8}{|c|}{ Average MAE } & 6.8941 \\
\hline
\end{tabular}

Table 10: Uniqueness presentation with twin multi-biometric identification

\begin{tabular}{|c|c|c|c|c|c|c|}
\hline \multirow[b]{2}{*}{ Twin } & \multicolumn{3}{|c|}{ Intra-class (handwriting) } & \multicolumn{3}{|c|}{ Intra-class (fingerprint) } \\
\hline & $\mathrm{a}$ & $\mathrm{b}$ & $\begin{array}{l}\text { Inter-class } \\
\text { (handwriting) }\end{array}$ & a & $\mathrm{b}$ & $\begin{array}{l}\text { Inter-class } \\
\text { (fingerprint) }\end{array}$ \\
\hline One twin & 0.69840 & 0.702700 & 0.755700 & 5.506100 & 5.752900 & 6.170300 \\
\hline 5 twin & 1.05090 & 1.038160 & 1.149260 & 3.159780 & 3.748200 & 4.427920 \\
\hline 10 twin & 0.98417 & 1.024620 & 1.310340 & 3.829320 & 2.313170 & 4.450940 \\
\hline 15 twin & 0.86576 & 1.001100 & 1.190767 & 4.544347 & 6.207867 & 9.690447 \\
\hline 20 twin & 1.07769 & 1.016375 & 1.296195 & 5.292855 & 5.780635 & 9.989795 \\
\hline
\end{tabular}




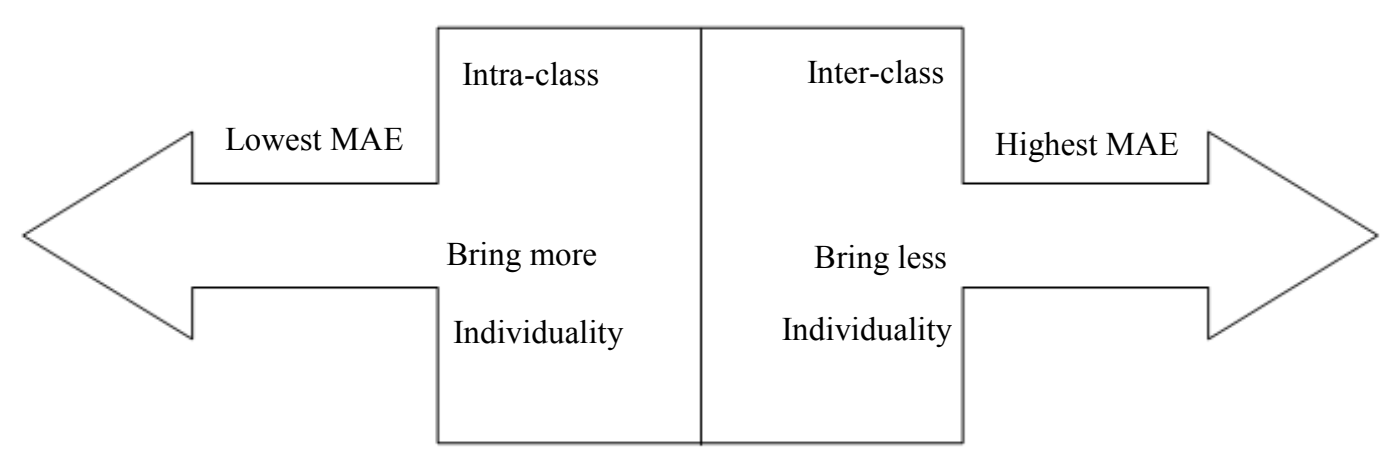

Fig. 6: Connection between MAE values

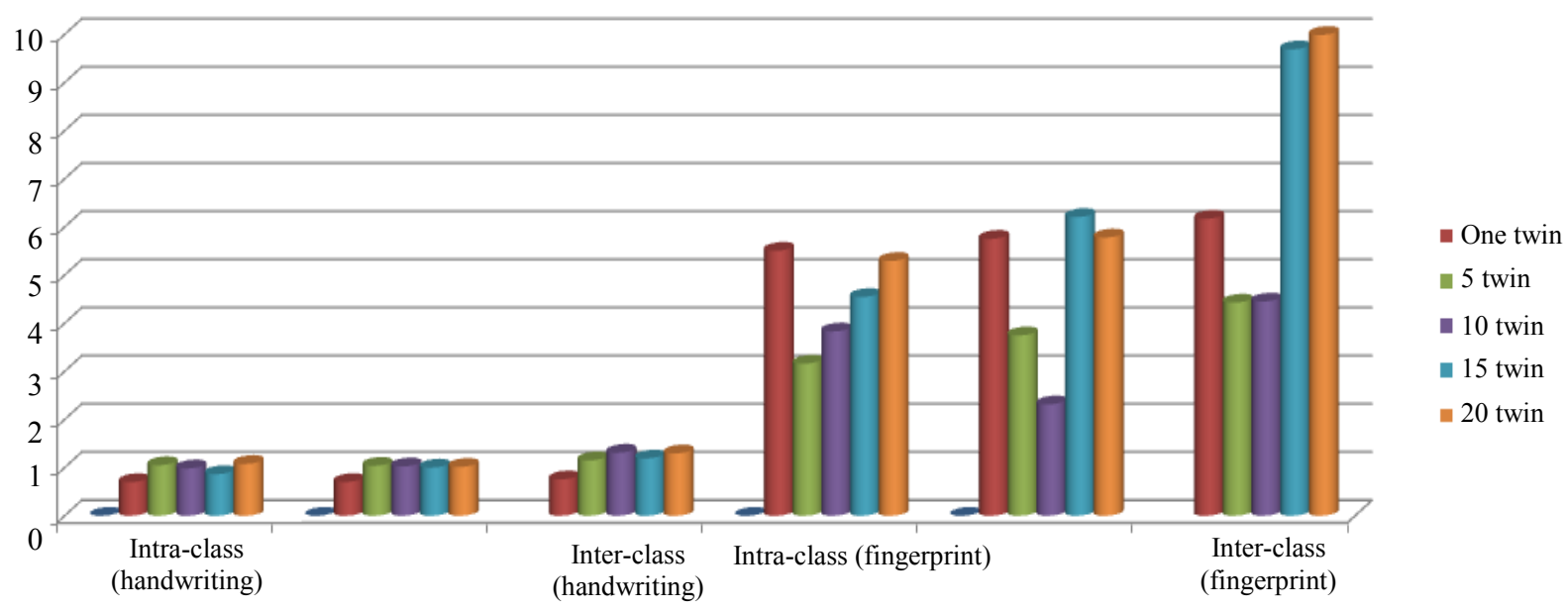

Fig. 7: Graph of Uniqueness presentation for AUMI

As such, AUMI's effectiveness in TMI feature extraction has been verified by the analysis of uniqueness presentation. Furthermore, in twin handwriting-fingerprint, the extracted feature appears to present the individual's distinct features.

The relation between these two values of MAE in technique capacity assessment for the discovery of the best technique is depicted in Fig. 6.

The notion of individuality in twin handwritingfingerprint requires that the similarity error is greater for inter-class (both twins) and lesser for intra-class (same person); Figure 7 can be referred. It appears that the features extracted with the AUMI algorithm are closer for the exact person in a twin but more dissimilar for different persons in a twin. This has led to lesser MAE value for intra- class while the MAE value for the interclass becomes larger, evidencing the practicability of the proposed technique in features extraction in the context of TI. Additionally, the notion of individuality relating to twin handwriting-fingerprint has been mentioned in several works including Eliabeth et al. (2015) and Pervouchine and Leedham (2007). Some empirical validation of individuality of twin multi-biometric with the AUMI algorithm of MF in the extraction of feature is offered in this work.

However, this section's result will not be considered in the best technique determination. Additionally, the next section will present the comparison of techniques. In particular, AUMI algorithm for the notion of individuality embraced by twin multi-biometric in the arena of TI will be validated. AUMI is practicable for the same person in a twin as well as for different persons in a twin. Also, three techniques also demonstrate their fittingness for the concept of twin multi-biometric, as can be seen from the outcomes they generate. Therefore, more in-depth exploration should be made on AUMI, UMI, Aspect, GMI technique of moment function as well as macro and geometrical minute with IT.

\section{Intra-Class (Same Person in a Twin) and Inter-Class (Both Persons in a Twin) Result and Performance between Techniques}

This section presents the outcomes generated by Macro, GMI, Aspect, UMI and AUMI in the context of twin handwriting. Geometrical minute, GMI, 
Aspect, UMI and AUMI are discussed in the context of twin fingerprint, with the additional inclusion of the findings of relevant study in order to determine the most fitting technique for twin handwritingfingerprint's individuality. AUMI's capacity in the extraction of features of twin handwritten-fingerprint word and shape image in the context of TI is examined in this study and the algorithm efficiently has fulfilled the individuality of the twin handwriting-fingerprint. For intra-class, similarity error is found to be smaller, while that of inter-class; it is found to be larger. Interclass and intra-class refers to both persons and the exact person, respectively, in a twin.

For intra-class, the analysis of variance between features generates lower value, as opposed to the analysis performed on inter-class, which demonstrates affirmation on the Individuality of twin handwritingfingerprint. Thus, for intra-class, the most advanced technique of individuality of twin handwritingfingerprint can be measured using the smallest MAE value. As for inter-class, the biggest MAE value is required for the measurement of similarity error, whereas for intra-class, the smallest MAE value is required for the same purpose. This demonstrates that the extracted features are the most linked and similar, while showing more characteristic of individuality inside a group of features. In the context of interclass, gaining the largest MAE value signifies that the features are very distinct from others, resulting in low individuality level in the dataset.

This section discusses the outcomes generated from the analysis of the intra-class and inter-class comprising MEA with mean and standard deviation (refer Tables 11 through 16). Four sets of samples for each biometric from 20 twins are employed.

\section{Intra-Class (Same twin) and Inter-Class (Different Twin) Result and Comparison Technique}

This section comprises the discussion on the outcomes obtained from the analysis on both the intraclass and inter-class. Tables 17 through 26 can be referred for the intra-class (same twin) and inter-class (different twin) outcomes. Here, four sets of handwriting and four sets of fingerprint from 20 twins are shown.

As evidenced by Tables 17-26, there is irregularity in terms of the technique arrangement for the lowest MAE value with mean and standard deviation, with the exception of AUMI. Here, AUMI shows the smallest MAE value in almost all tables. A technique must be consistent so that intra-class and inter-class can be compared with one another, which will lead to the determination of the best technique. The best technique concurrently has the smallest MAE value for intra-class and the biggest MAE value for interclass. Among the tested techniques in this study, AUMI is the best technique. The value scale for the extracted invariant feature vector produced by feature extraction contains characteristics that are different. As proof, in comparison to other techniques, AUMI will generate the smallest value for invariant feature vector, demonstrating its consistency in generating the smallest MAE value for intra-class and biggest MAE value for inter-class, as shown in Table 27.

Table 11: Calculation of mean and standard deviation for AUMI

\begin{tabular}{|c|c|c|c|c|c|c|c|c|c|c|}
\hline \multirow[b]{2}{*}{ Twin } & \multicolumn{2}{|c|}{ Intra-class (handwriting) } & \multicolumn{2}{|c|}{ Intra-class (fingerprint) } & \multirow[b]{2}{*}{ Mean } & \multirow[b]{2}{*}{$\begin{array}{l}\text { Standard } \\
\text { deviation }\end{array}$} & \multirow[b]{2}{*}{$\begin{array}{l}\text { Inter-class } \\
\text { (handwriting) }\end{array}$} & \multirow[b]{2}{*}{$\begin{array}{l}\text { Inter-class } \\
\text { (fingerprint) }\end{array}$} & \multirow[b]{2}{*}{ Mean } & \multirow[b]{2}{*}{$\begin{array}{l}\text { Standard } \\
\text { deviation }\end{array}$} \\
\hline & $\mathrm{a}$ & $\mathrm{b}$ & $\mathrm{a}$ & $\mathrm{b}$ & & & & & & \\
\hline One twin & 0.698400 & 0.702700 & 5.506100 & 5.752900 & 3.165025 & 2.847514 & 0.755700 & 6.170300 & 3.463000 & 3.828700 \\
\hline 5 twins & 1.050900 & 1.038160 & 3.159780 & 3.748200 & 2.249260 & 1.411701 & 1.149260 & 4.427920 & 2.788590 & 2.318363 \\
\hline 10 twins & 0.984170 & 1.024620 & 3.829320 & 2.313170 & 2.037820 & 1.344376 & 1.310340 & 4.450940 & 2.880640 & 2.220740 \\
\hline 15 twins & 0.865760 & 1.001100 & 4.544347 & 6.207867 & 3.154769 & 2.653940 & 1.190767 & 9.690447 & 5.440607 & 6.010181 \\
\hline 20 twins & 1.077690 & 1.016375 & 5.292855 & 5.780635 & 3.291889 & 2.599895 & 1.296195 & 9.989795 & 5.642995 & 6.147304 \\
\hline Mean & 0.935384 & 0.956591 & 4.466480 & 4.760554 & 2.779752 & & 1.140452 & 6.945880 & 4.043166 & \\
\hline $\begin{array}{l}\text { Standard } \\
\text { deviation }\end{array}$ & 0.155711 & 0.142563 & 0.985293 & 1.668426 & & 0.730530 & 0.225700 & 2.736989 & & 1.911777 \\
\hline
\end{tabular}

Table 12: Calculation of mean and standard deviation for GMI

\begin{tabular}{|c|c|c|c|c|c|c|c|c|c|c|}
\hline \multirow[b]{2}{*}{ Twin } & \multicolumn{2}{|c|}{ Intra-class (handwriting) } & \multicolumn{2}{|c|}{ Intra-class (fingerprint) } & \multirow[b]{2}{*}{ Mean } & \multirow[b]{2}{*}{$\begin{array}{l}\text { Standard } \\
\text { deviation }\end{array}$} & \multirow[b]{2}{*}{$\begin{array}{l}\text { Inter-class } \\
\text { (handwriting) }\end{array}$} & \multirow[b]{2}{*}{$\begin{array}{l}\text { Inter-class } \\
\text { (fingerprint) }\end{array}$} & \multirow[b]{2}{*}{ Mean } & \multirow[b]{2}{*}{$\begin{array}{l}\text { Standard } \\
\text { deviation }\end{array}$} \\
\hline & a & $\mathrm{b}$ & $\mathrm{a}$ & $\mathrm{b}$ & & & & & & \\
\hline One twin & 5.573000 & 3.505300 & 4.548600 & 5.124400 & 4.687825 & 0.892913 & 2.80040 & 15.38670 & 9.093550 & 8.899858 \\
\hline 5 twins & 5.017060 & 3.920140 & 45.78400 & 50.08234 & 26.20089 & 25.15955 & 3.28166 & 33.31978 & 18.30072 & 21.24016 \\
\hline 10 twins & 4.198270 & 3.981390 & 56.70813 & 41.93724 & 26.70626 & 26.80251 & 3.04288 & 33.67116 & 18.35702 & 21.65746 \\
\hline 15 twins & 4.313453 & 4.183793 & 54.17597 & 37.29115 & 24.99109 & 24.92360 & 3.073113 & 33.30669 & 18.18990 & 21.37837 \\
\hline 20 twins & 5.835410 & 4.333975 & 47.34950 & 43.76792 & 25.32170 & 23.42141 & 3.387275 & 30.59107 & 16.98917 & 19.23599 \\
\hline Mean & 4.987439 & 3.984920 & 41.71324 & 35.64061 & 21.58155 & & 3.117066 & 29.25508 & 16.18607 & \\
\hline $\begin{array}{l}\text { Standard } \\
\text { deviation }\end{array}$ & 0.731413 & 0.314497 & 21.27037 & 17.66513 & & 10.88159 & 0.227935 & 7.851050 & & 5.390356 \\
\hline
\end{tabular}


Table 13: Calculation of mean and standard deviation for Aspect

\begin{tabular}{|c|c|c|c|c|c|c|c|c|c|c|}
\hline \multirow[b]{2}{*}{ Twin } & \multicolumn{2}{|c|}{ Intra-class (handwriting) } & \multicolumn{2}{|c|}{ Intra-class (fingerprint) } & \multirow[b]{2}{*}{ Mean } & \multirow{2}{*}{$\begin{array}{l}\text { Standard } \\
\text { deviation }\end{array}$} & \multirow{2}{*}{$\begin{array}{l}\text { Inter-class } \\
\text { (handwriting) }\end{array}$} & \multirow{2}{*}{$\begin{array}{l}\text { Inter-class } \\
\text { (fingerprint) }\end{array}$} & \multirow[b]{2}{*}{ Mean } & \multirow{2}{*}{$\begin{array}{l}\text { Standard } \\
\text { deviation }\end{array}$} \\
\hline & $\mathrm{a}$ & $\mathrm{b}$ & $\mathrm{a}$ & $\mathrm{b}$ & & & & & & \\
\hline One twin & 1.447500 & 0.949700 & 14.06670 & 4.926600 & 5.347625 & 6.075970 & 1.362900 & 4.861300 & 3.112100 & 2.473742 \\
\hline 5 twins & 2.865500 & 2.455080 & 82.39698 & 53.19492 & 35.22812 & 39.45089 & 1.480800 & 46.90434 & 24.19257 & 32.11929 \\
\hline 10 twins & 3.410860 & 3.198690 & 55.34073 & 41.42899 & 25.84482 & 26.63960 & 1.841810 & 32.16461 & 17.00321 & 21.44146 \\
\hline 15 twins & 1.824000 & 4.108500 & 57.11473 & 34.93319 & 24.49511 & 26.47380 & 1.587900 & 1.824000 & 1.705950 & 0.166948 \\
\hline 20 twins & 4.913280 & 2.687370 & 60.59422 & 44.48573 & 28.17015 & 28.91235 & 2.200155 & 4.913280 & 3.556718 & 1.918469 \\
\hline Mean & 2.892228 & 2.679868 & 53.90267 & 35.79389 & 23.81716 & & 1.694713 & 18.13351 & 9.914110 & \\
\hline $\begin{array}{l}\text { Standard } \\
\text { deviation }\end{array}$ & 1.376835 & 1.156961 & 24.77899 & 18.46367 & & 12.10177 & 0.333308 & 20.25808 & & 14.36687 \\
\hline
\end{tabular}

Table 14: Calculation of mean and standard deviation for UMI

\begin{tabular}{|c|c|c|c|c|c|c|c|c|c|c|}
\hline \multirow[b]{2}{*}{ Twin } & \multicolumn{2}{|c|}{ Intra-class (handwriting) } & \multicolumn{2}{|c|}{ Intra-class (fingerprint) } & \multirow[b]{2}{*}{ Mean } & \multirow[b]{2}{*}{$\begin{array}{l}\text { Standard } \\
\text { deviation }\end{array}$} & \multirow[b]{2}{*}{$\begin{array}{l}\text { Inter-class } \\
\text { (handwriting) }\end{array}$} & \multirow[b]{2}{*}{$\begin{array}{l}\text { Inter-class } \\
\text { (fingerprint) }\end{array}$} & \multirow[b]{2}{*}{ Mean } & \multirow[b]{2}{*}{$\begin{array}{l}\text { Standard } \\
\text { deviation }\end{array}$} \\
\hline & $\mathrm{a}$ & $\mathrm{b}$ & $\begin{array}{l}--- \\
\mathrm{a}\end{array}$ & $\mathrm{b}$ & & & & & & \\
\hline One twin & 0.015100 & 0.005100 & 0.320000 & 0.855700 & 0.298975 & 0.398887 & 0.007600 & 0.380300 & 0.193950 & 0.263539 \\
\hline 5 twins & 0.013760 & 0.015220 & 0.715680 & 0.456020 & 0.300170 & 0.346490 & 0.009760 & 0.327580 & 0.168670 & 0.224733 \\
\hline 10 twins & 0.015150 & 0.013190 & 0.698400 & 0.453700 & 0.295110 & 0.339436 & 0.009930 & 0.495920 & 0.252925 & 0.343647 \\
\hline 15 twins & 0.015620 & 0.015547 & 0.779427 & 1.568773 & 0.594842 & 0.742450 & 0.010133 & 0.646620 & 0.328377 & 0.450064 \\
\hline 20 twins & 0.025195 & 0.013455 & 0.710440 & 1.269090 & 0.504545 & 0.604943 & 0.012370 & 0.549525 & 0.280948 & 0.379826 \\
\hline Mean & 0.016965 & 0.012502 & 0.644789 & 0.920657 & 0.398728 & & 0.009959 & 0.479989 & 0.244974 & \\
\hline $\begin{array}{l}\text { Standard } \\
\text { deviation }\end{array}$ & 0.004653 & 0.004267 & 0.184272 & 0.494878 & & 0.179197 & 0.001692 & 0.128473 & & 0.090215 \\
\hline
\end{tabular}

Table 15: Calculation of mean and standard deviation for Macro

\begin{tabular}{|c|c|c|c|c|c|c|c|}
\hline \multirow[b]{2}{*}{ Twin } & \multicolumn{7}{|c|}{ Intra-class (handwriting) } \\
\hline & a & $\mathrm{b}$ & Mean & $\begin{array}{l}\text { Standard } \\
\text { deviation }\end{array}$ & $\begin{array}{l}\text { Inter-class } \\
\text { (handwriting) }\end{array}$ & Mean & $\begin{array}{l}\text { Standard } \\
\text { deviation }\end{array}$ \\
\hline One twin & 0.694100 & 0.284200 & 0.489150 & 0.289843 & 0.505700 & 0.505700 & 0.505700 \\
\hline 5 twins & 0.645760 & 0.547220 & 0.596490 & 0.069678 & 0.405180 & 0.405180 & 0.405180 \\
\hline 10 twins & 0.699420 & 0.553160 & 0.626290 & 0.103421 & 0.417180 & 0.417180 & 0.417180 \\
\hline 15 twins & 0.673300 & 0.638387 & 0.655844 & 0.024687 & 0.429180 & 0.429180 & 0.429180 \\
\hline 20 twins & 0.710505 & 0.674430 & 0.692468 & 0.025509 & 0.433245 & 0.433245 & 0.433245 \\
\hline Mean & 0.684617 & 0.539479 & 0.612048 & & 0.438097 & 0.438097 & \\
\hline Standard deviation & 0.025579 & 0.152814 & & 0.109725 & 0.039352 & & 0.039352 \\
\hline
\end{tabular}

Table 16: Calculation of mean and standard deviation for Geometrical minute

\begin{tabular}{|c|c|c|c|c|c|c|c|}
\hline \multirow[b]{2}{*}{ Twin } & \multicolumn{7}{|c|}{ Intra-class (fingerprint) } \\
\hline & $\begin{array}{l}--- \\
\mathrm{a}\end{array}$ & $\mathrm{b}$ & Mean & $\begin{array}{l}\text { Standard } \\
\text { deviation }\end{array}$ & $\begin{array}{l}\text { Inter-class } \\
\text { (fingerprint) }\end{array}$ & Mean & $\begin{array}{l}\text { Standard } \\
\text { deviation }\end{array}$ \\
\hline One twin & 51.56250 & 75.62500 & 63.59375 & 17.01476 & 32.45310 & 32.45310 & 32.45310 \\
\hline 5 twins & 46.82500 & 57.32500 & 52.07500 & 7.424621 & 28.77500 & 28.77500 & 28.77500 \\
\hline 10 twins & 57.22863 & 45.55857 & 51.39360 & 8.251979 & 31.39877 & 31.39877 & 31.39877 \\
\hline 15 twins & 32.12500 & 27.62500 & 29.87500 & 3.181981 & 23.96880 & 23.96880 & 23.96880 \\
\hline 20 twins & 46.55494 & 42.64804 & 44.60149 & 2.762595 & 26.78768 & 26.78768 & 26.78768 \\
\hline Mean & 46.85921 & 49.75632 & 48.30777 & & 28.67667 & 28.67667 & \\
\hline Standard deviation & 9.311773 & 17.91939 & & 5.743082 & 3.442864 & & 3.442864 \\
\hline
\end{tabular}

Table 17: Calculation of mean and standard deviation for AUMI with Intra-class and Inter-class for handwriting

\begin{tabular}{llll}
\hline AUMI & Mean intra-class & standard deviation intra-class \\
\hline Twin $(1,2)$ & 0.662400 & 0.066750880 & Inter-class \\
Twin $(1, \ldots, 5)$ & 0.959400 & 0.561415711 & 0.8822 \\
Twin $(1, \ldots, 10)$ & 1.215410 & 0.772118980 & 1.3235 \\
Twin $(1, \ldots, 15)$ & 1.134663 & 0.762484227 & 2.6528 \\
Twin $(1, \ldots, 20)$ & 1.159055 & 0.697907828 & 1.3437 \\
\hline
\end{tabular}

Table 18: Calculation of mean and standard deviation for UMI with Intra-class and Inter-class for handwriting

\begin{tabular}{llll}
\hline UMI & Mean Intra-class & Standard deviation intra-class & Inter-class \\
\hline Twin $(1,2)$ & 0.01015 & 0.003323402 & 0.0046 \\
Twin $(1, \ldots, 5)$ & 0.0098 & 0.00429127 & 0.0018 \\
Twin $(1, \ldots, 10)$ & 0.009045 & 0.005909362 & 2.6528 \\
Twin $(1, \ldots, 15)$ & 0.010147 & 0.005398501 & 0.0018 \\
Twin $(1, \ldots, 20)$ & 0.01298 & 0.012503246 & 0.0015 \\
\hline
\end{tabular}


Bayan Omar Mohammed and Siti Mariyam Shamsuddin / Journal of Computer Science 2018, 14 (1): 92.107 DOI: 10.3844/jessp.2018.92.107

Table 19: Calculation of mean and standard deviation for GMI with Intra-class and Inter-class for handwriting

\begin{tabular}{llll}
\hline GMI & Mean Intra-class & standard deviation intra-class & Inter-class \\
\hline Twin $(1,2)$ & 4.906600 & 1.885712 & 2.1638 \\
Twin $(1, \ldots, 5)$ & 3.436220 & 1.722402 & 2.4285 \\
Twin $(1, \ldots, 10)$ & 3.120160 & 1.576148 & 0.6372 \\
Twin $(1, \ldots, 15)$ & 2.929344 & 1.676507 & 0.3585 \\
Twin $(1, \ldots, 20)$ & 3.494950 & 1.808673 & 0.2493 \\
\hline
\end{tabular}

Table 20: Calculation of mean and standard deviation for Aspect with Intra-class and Inter-class for handwriting

\begin{tabular}{llll}
\hline Aspect & Mean Intra-class & standard deviation intra-class & Inter-class \\
\hline Twin $(1,2)$ & 1.3273000 & 0.066185 & 1.038900 \\
Twin $(1, \ldots, 5)$ & 1.2769400 & 0.524883 & 0.615900 \\
Twin $(1, \ldots, 10)$ & 1.7398800 & 0.752517 & 0.280600 \\
Twin $(1, \ldots, 15)$ & 1.5595375 & 0.663759 & 0.196000 \\
Twin $(1, \ldots, 20)$ & 2.1491900 & 0.168500 & 2.221547 \\
\hline
\end{tabular}

Table 21: Calculation of mean and standard deviation for Macro with Intra-class and Inter-class for handwriting

\begin{tabular}{llll}
\hline Macro & Mean Intra-class & standard deviation intra-class & Inter-class \\
\hline Twin $(1,2)$ & 0.47075 & 0.049426764 & 0.2879 \\
Twin $(1, \ldots, 5)$ & 0.40518 & 0.094443142 & 0.1375 \\
Twin $(1, \ldots, 10)$ & 0.41718 & 0.148020521 & 0.4553 \\
Twin $(1, \ldots, 15)$ & 0.41718 & 0.087087560 & 0.1960 \\
Twin $(1, \ldots, 20)$ & 0.46161 & 0.146029730 & 0.0419 \\
\hline
\end{tabular}

Table 22: Calculation of mean and standard deviation for AUMI with Intra-class and Inter-class for fingerprint

\begin{tabular}{llll}
\hline AUMI & Mean Intra-class & standard deviation intra-class & Inter-class \\
\hline Twin $(1,2)$ & 3.737950 & 2.991415238 & 6.8941 \\
Twin $(1, \ldots, 5)$ & 4.364500 & 1.765268414 & 6.1811 \\
Twin $(1, \ldots, 10)$ & 3.909640 & 1.625751286 & 6.7887 \\
Twin $(1, \ldots, 15)$ & 4.354938 & 3.100190322 & 7.3110 \\
Twin $(1, \ldots, 20)$ & 4.587275 & 2.720654340 & 7.2035 \\
\hline
\end{tabular}

Table 23: Calculation of mean and standard deviation for UMI with Intra-class and Inter-class for fingerprint

\begin{tabular}{llll}
\hline UMI & Mean Intra-class & standard deviation intra-class & Inter-class \\
\hline Twin $(1,2)$ & 0.250700 & 0.183282078 & 0.1191 \\
Twin $(1, \ldots, 5)$ & 0.327580 & 0.267001361 & 0.0673 \\
Twin $(1, \ldots, 10)$ & 0.419910 & 0.481040616 & 0.0317 \\
Twin $(1, \ldots, 15)$ & 0.595947 & 0.617032208 & 0.0299 \\
Twin $(1, \ldots, 20)$ & 0.487162 & 0.556085108 & 0.0199 \\
\hline
\end{tabular}

Table 24: Calculation of mean and standard deviation for GMI with Intra-class and Inter-class for fingerprint

\begin{tabular}{llll}
\hline GMI & Mean Intra-class & standard deviation intra-class & Inter-class \\
\hline Twin $(1,2)$ & 28.98820 & 19.23543 & 14.8771 \\
Twin $(1, \ldots, 5)$ & 33.31978 & 16.86477 & 6.53870 \\
Twin $(1, \ldots, 10)$ & 33.67116 & 13.06800 & 4.12390 \\
Twin $(1, \ldots, 15)$ & 33.30669 & 12.38446 & 42.1358 \\
Twin $(1, \ldots, 20)$ & 30.59107 & 12.13054 & 2.02350 \\
\hline
\end{tabular}

Table 25: Calculation of mean and standard deviation for aspect with Intra-class and Inter-class for fingerprint

\begin{tabular}{llll}
\hline Aspect & Mean Intra-class & standard deviation intra-class & Inter-class \\
\hline Twin $(1,2)$ & 4.858066667 & 3.6802 & 3.430599 \\
Twin $(1, \ldots, 5)$ & 46.90434000 & 3.6804 & 85.41617 \\
Twin $(1, \ldots, 10)$ & 32.16461000 & 1.8467 & 59.72388 \\
Twin $(1, \ldots, 15)$ & 29.40896667 & 1.3589 & 49.08535 \\
Twin $(1, \ldots, 20)$ & 34.26115000 & 1.2451 & 49.16043 \\
\hline
\end{tabular}


Table 26: Calculation of mean and standard deviation for geometrical minute with Intra-class and Inter-class for fingerprint

\begin{tabular}{llll}
\hline Geometrical minute & Mean Intra-class & standard deviation intra-class & Inter-class \\
\hline Twin $(1,2)$ & 27.13280 & 7.524040416 & 19.6758 \\
Twin $(1, \ldots, 5)$ & 28.77500 & 4.397706389 & 7.31250 \\
Twin $(1, \ldots, 10)$ & 28.10781 & 4.806303191 & 3.92480 \\
Twin $(1, \ldots, 15)$ & 26.13646 & 5.544032737 & 2.91630 \\
Twin $(1, \ldots, 20)$ & 25.14220 & 5.831024929 & 2.29570 \\
\hline
\end{tabular}

Table 27: Mean for All techniques

Mean

\begin{tabular}{lll} 
Techniques & Intra-class & Inter-class \\
\hline AUMI & 2.779752 & 4.043166 \\
GMI & 21.58155 & 16.18607 \\
Aspect & 23.81716 & 9.914110 \\
UMI & 0.398728 & 0.244974 \\
Macro & 0.612048 & 0.438097 \\
Geometrical minute & 48.30777 & 28.67667 \\
Standard deviation & & \\
AUMI & 0.730530 & 1.911777 \\
GMI & 10.88159 & 5.390356 \\
Aspect & 12.10177 & 14.36687 \\
UMI & 0.179197 & 0.090215 \\
Macro & 0.109725 & 0.039352 \\
Geometrical minute & 5.743082 & 3.442864 \\
\hline
\end{tabular}

\section{Conclusion}

A novel framework for identical twins is introduced in this study. The proposed framework utilises a technique known as AUMI in its determination of individuality in identical twin multi-biometric. AUMI provides the verification to twin multi-biometric in twin Identification (TI) fulfilling the individuality requirement. Representation of individuality is the focal point of this study, specifically the individuality of twin multibiometric which is illustrated by Moment Function (MF) during the extraction of feature. The representation of individuality is elaborated in terms of procedure. Also, the technique deemed most applicable is recommended. In the context of this study, the technique in question involves mean and standard division calculation between the smallest and biggest MAE value. In terms of the extracted features, each technique acquires distinctive value of scale. The obtained outcomes show that AUMI produces the highest individuality. This study also scrutinises other techniques of moment in multibiometric twin identification.

\section{Acknowledgement}

The authors wish to thank anonymous reviewers for their valuable, insightful comments that improve the content of this review paper. The authors also wish to thank University Technology Malaysia (UTM) which provided the facilities and appropriate environments for carrying out this study.

\section{Funding Information}

This research is funded by Malaysia's Ministry of Higher Education, University Technology Malaysia (UTM).

\section{Author's Contributions}

Bayan Omar Mohammed: Designed the literature review plan and organized the study and contributed to the writing of the manuscript.

Siti Mariyam Shamsuddin: The main research supervisor, advised and supervised in the review process of this systematic study.

\section{Ethics}

The corresponding author confirms that the other authors have read and approved the manuscript and there is no ethical issue involved. This paper is original and contains unpublished material.

\section{References}

Azah, K.M., S.M. Shamsuddin and A. Abrahamz, 2010. Improvement of authorship invarianceness for individuality representation in writer identification. ICS AS, 3: 371-387.

Chen, C.C., 1993. Improved moment invariants for shape discrimination. Patt. Recognit., 26: 683-686. DOI: 10.1016/0031-3203(93)90121

Easwaramoorthy, S., F. Sophia and A. Prathik, 2016. Biometric authentication using finger nails. Proceedings of the International Conference on Emerging Trends in Engineering, Technology and Science, Feb. 24-26, IEEE Xplore Press, Pudukkottai, India, pp: 1-6. DOI: 10.1109/ICETETS.2016.7603054

Eliabeth, S., B. Thomas and J.J. Kizhakkethottam, 2015. Analysis of effective biometric identification on monozygotic twins. Proceedings of the International Conference on Soft-Computing and Networks Security, Feb. 25-27, IEEE Xplore Press, Coimbatore, India, pp: 1-6. DOI: 10.1109/ICSNS.2015.7292444

Feng, P. and M. Keane, 1994. A new set of moment invariants for handwritten numeral recognition. Proceedings of the IEEE International Conference of Image Processing, Nov. 13-16, IEEE Xplore Press, Austin, TX, USA, pp: 154-158.

DOI: $10.1109 /$ ICIP.1994.413294 
Hamid, B. and K. Faez, 2013. Introducing a new multimodal database from twins' biometric traits. Proceedings of the 21st Iranian Conference on Electrical Engineering, May 14-16, IEEE Xplore Press, Mashhad, Iran, pp: 1-6. DOI: 10.1109/IranianCEE.2013.6599528

Hu, M.K., 1962. Visual pattern recognition by moment invariants. IRE Trans. Inform. Theory, 8: 179-187. DOI: 10.1109/TIT.1962.1057692

Jain, A.K., S. Prabhakar and S. Pankanti, 2002. On the similarity of identical twin fingerprints. Patt. Recognit., 35: 2653-2663. DOI: $10.1016 / \mathrm{S} 0031-3203(01) 00218-7$

Jain, K., S. Prabhakar and S. Pankanti, 2001. Twin test: On discriminability of fingerprints. Proceedings of the International Conference on Audio- and VideoBased Biometric Person Authentication, (BPA' 01), Springer, pp: 211-217. DOI: 10.1007/3-540-45344-X_30

Karahan, S., M.K. Yildirum, K. Kïrtac, F.S. Rende and G. Butun et al., 2016. How image degradations affect deep CNN-based face recognition. Proceedings of the International Conference of the Biometrics Special Interest Group, Sep. 21-23, IEEE Xplore Press, Darmstadt, Germany, pp: 1-5. DOI: 10.1109/BIOSIG.2016.7736924

Kauba, C., E. Piciucco, E. Maiorana, P. Campisi and A. Uhl, 2016. Advanced variants of feature level fusion for finger vein recognition. Proceedings of the International Conference of the Biometrics Special Interest Group, Sep. 21-23, IEEE Xplore Press, Darmstadt, Germany, pp: 1-7.

DOI: 10.1109/BIOSIG.2016.7736908

Koda, Y., T. Higuchi and A.K. Jain, 2016. Advances in capturing child fingerprints: A high resolution CMOS image sensor with SLDR method. Proceedings of the International Conference of the Biometrics Special Interest Group, Sep. 21-23, IEEE Xplore Press, Darmstadt, Germany, pp: 1-4. DOI: 10.1109/BIOSIG.2016.7736909

Leng, W.Y. and S.M. Shamsuddin, 2012. Fingerprint identification using discretization technique. Int. J. Comput. Electr. Automat. Control Inform. Eng., 6: 240-248.

Liu, Y. and S.N. Srihari, 2009. A computational discriminability analysis on twin fingerprints. Proceedings of the International Workshop on Computational Forensics, (WCF' 09), Springer, pp: 43-54. DOI: 10.1007/978-3-642-03521-0_5

Muhammed, B.O. and S.M. Shamsuddin, 2012. Improvement in twins handwriting identification with invariants discretization. EURASIP J. Adv. Signal Process., 48: 1-12.

DOI: $10.1186 / 1687-6180-2012-48$
Muhammed, B.O. and S.M. Shamsuddin, 2017. Twins multimodal biometric identification system with aspect united moment invariant. J. Theoretical Applied Inform. Technol., 95: 788-803.

Narayanan, A. and V. Shmatikov, 2005. Fast dictionary attacks on passwords using time-space tradeoff. Proceedings of the 12th ACM Conference on Computer and Communication Security, Nov. 07-11, ACM, Alexandria, VA, USA, pp: 364-372. DOI: $10.1145 / 1102120.1102168$

Nejati, H., L. Zhang, T. Sim E. Martinez- Marroquin and G. Dong, 2012. Wonder Ears: Identification of identical twins from ear images. Proceedings of the 21 st International Conference on Pattern Recognition, Nov. 11-15, IEEE Xplorev Press, Tsukuba, Japan, pp: 1201-1204.

Neves, J. and H. Proenc, 2016. ICB-RW 2016: International challenge on biometric recognition in the wild. Proceedings of the International Conference on Biometrics, Jun. 13-16, IEEE Xplore Press, Halmstad, Sweden, pp: 1-6. DOI: $10.1109 /$ ICB.2016.7550066

Paone, J.R., P.J. Flynn, P.J. Philips, K.W. Bowyer and R.W. VorderBruegge et al., 2014. Double trouble: Differentiating identical twins by face recognition. IEEE Trans. Inform. Forens. Security, 9: 285-295. DOI: 10.1109/TIFS.2013.2296373

Patil, P.M. and R.B. Wagh, 2016. Writer's Identification by using word reason feature transform. Proceedings of the International Conference on Emerging Trends in Engineering, Technology and Science, Feb. 2426, IEEE Xplore Press, Pudukkottai, India, pp: 1-4. DOI: 10.1109/ICETETS.2016.7602992

Patil, S.S., S. Gudasalamani, N.C. Iyer and V.G. Garagad, 2016. Tilt and scale invariant iris recognition system. Proceedings of the IEEE International Conference on Current Trends in Advanced Computing, Mar. 10-11, IEEE Xplore Press, Bangalore, India, pp: 1-6. DOI: 10.1109/ICCTAC.2016.7567342

Pervouchine, V. and G. Leedham, 2007. Extraction and analysis of forensic document examiner features used for writer identification. Patt. Recognit., 40: 1004-1013. DOI: 10.1016/j.patcog.2006.08.008

Srinivas, N., G. Aggarwal, P.J. Flynn and R.W.V. Bruegge, 2012. Analysis of facial marks to distinguish between identical twins. IEEE Trans. Inform. Forens. Security, 7: 1536-1550. DOI: 10.1109/TIFS.2012.2206027

Umair, M.K., A.K. Shoab, N. Ejaz and R. Riaz, 2009. A fingerprint verification system using minutiae and wavelet based features. Proceedings of the International Conference on Emerging Technologies, Oct. 19-20, IEEE Xplore Press, Islamabad, Pakistan, pp: 291-296.

DOI: 10.1109/ICET.2009.5353157 
Vipin, V., K.W. Bowyer, P.J. Flynn, D. Huang and L. Chen et al., 2011. Twins 3D face recognition challenge. Proceedings of the International Joint Conference on Biometrics, Oct. 11-13, IEEE Xplore Press, Washington, DC, USA, pp: 1-7. DOI: $10.1109 /$ IJCB.2011.6117491

Yinan, S., L. Weijun and W. Yuechao, 2003. United moment invariants for shape discrimination. Proceedings of the IEEE International Conference on Robotics, Intelligent Systems and Signal Processing, Oct. 8-13, IEEE Xplore Press, Changsha, Hunan, China, pp: 88-93. DOI: 10.1109/RISSP.2003.1285554
Zhang, D.S. and G. Lu, 2002. Generic fourier descriptor for shape-based image retrieval. Proceedings of the IEEE International Conference on Multimedia and Expo, Aug. 26-29, IEEE Xplore Press, Lausanne, Switzerland, pp: 425-428.

DOI: 10.1109/ICME.2002.1035809 